\title{
Self-Contained Optical Enhancement Film for Printed Photovoltaics
}

\author{
Jan A. Mayer ${ }^{\mathrm{a}, *}$, Benjamin Gallinet ${ }^{\mathrm{a}}$, Ton Offermans ${ }^{\mathrm{a}, * *}$ Igor Zhurminsky $^{\mathrm{a}}$, \\ Rolando Ferrini ${ }^{\mathrm{a}}$ \\ ${ }^{a}$ CSEM, Center Muttenz, Tramstrasse 99 \\ 4132 Muttenz, Switzerland
}

\begin{abstract}
Printed photovoltaics promise lightweight and flexible light harvesting devices for conformal integration into buildings, portable electronics or vehicles. This is enabled by employing thin photoactive layers, which can reduce the use of sometimes costly and scarce absorber materials. Since this in turn comes along with an incomplete light absorption and hence restrains the power conversion efficiency of printed photovoltaics, their development was since long accompanied by integrated light management. However, besides a mere efficiency enhancement, new strategies should consider both functionality and additional costs of the light management. Optical enhancement strategies should consequently avoid complications with the delicate printing of the photovoltaic layers and therefore structures on the light incident surface of the device have been proposed. However, these air-faced approaches are prone to the impacts and stress of operating conditions and hence a protected solution is desired. Here we introduce a carefully designed photonic nanostructure embedded in a self-contained transparent film, which offers a conformal device attachment. An efficiency enhancement of $11 \%$ is demonstrated on an organic photovoltaic device. Angle dependent measurements moreover suggest a yearly increase of $13 \%$, exploiting the seasonal asymmetry of the incident solar power by a built-in asymmetric
\end{abstract}

\footnotetext{
* Corresponding author

${ }^{* *}$ Corresponding author

Email addresses: jmr@csem.ch (Jan A. Mayer), tof@csem.ch (Ton Offermans)
}

Preprint submitted to Solar Energy Materials and Solar Cells

December 23, 2016

C) 2017. This manuscript version is made available under the Elsevier user license http://www.elsevier.com/open-access/userlicense/1.0/ 
diffraction.

Keywords: light management, printed photovoltaics, absorption

enhancement, light trapping, organic solar cells, embedded nanostructure

\section{Introduction}

Certified record efficiencies for printable photovoltaic technologies are ranging between 22-23\% for CIGS, CdTe and perovskite solar cells [1, 2, 3] and between 10-13\% for CZTS, dye-sensitized and organic solar cells. 4, 5, 6, 7.

5 The continuous improvements during the past years were enabled on the one hand through material and process development [8, 9, 10] and on the other hand by a wide variety of optical enhancement schemes. [11, 12, 13, Existing solutions have thereby often been introduced as scattering or diffractive structures in the vicinity of or even directly in the active layer, in order to obtain coupling into guided modes. [14, 15, 16] If metallic layers are involved, surface plasmon polaritons can additionally be excited which in turn can give rise to strong confined fields in the absorber layer. [17, 18, 19] However, light management strategies should ideally neither compromise the electronic properties of the solar cell [20, 21] nor add costs or complications to the large-area fabrication of the photovoltaic devices. 12, 14, 22, Whereas the implementation of structures inside the functional photovoltaic layers could hinder appropriate morphology and phase formation, increase interface recombination or introduce additional parasitic absorption in the device, light management structures located on the surface provide an excellent alternative solution. Absorption

20 enhancements through light redirection and antireflection strategies have been reported [23, 24, 25, 26, 27, 28, 29, 30, 31, 32, which successfully avoid manipulation of the printed functional layers. However, these structures have their functional optical interface exposed to air and hence cannot sustain typically outdoor conditions of printed photovoltaic operation without losses in their optical properties. Up to now, only a single approach provided a protected surface structure that is designed with an unstructured air interface, but with efficiency 
enhancement only below $7 \%$. 33

Here we propose a self-standing and non-absorbent light management film with an unstructured sunward surface, which can be independently attached to the substrate of thin film photovoltaics. The film consists of a carefully designed high refractive index periodic nanostructure of large aspect-ratio, which is embedded in a polymer matrix to protect it from external influences and contamination. By introducing an optimized asymmetric shape, a large portion of the light is diffracted into the first order 34 and is further trapped in the device.

35 The structure generates a $11 \%$ enhancement in the power conversion efficiency (PCE) of an organic photovoltaic device printed in ambient atmosphere.

\section{Optical simulations}

The commercial software SETFOS (Fluxim AG, Switzerland) was used to calculate the optical properties of the solar cell. The absorption in the active

40 layer is determined dependent on the propagation angle in the substrate $\theta_{S}$, which is the angle accessible through light redirection structures. Secondly, for each geometry of the $\mathrm{ZnS}$ nanostructure (see Fig. S1), the diffraction efficiencies $\eta_{m}$ and the resulting propagation angles up to the fourth order $m= \pm 4$ were calculated for both polarizations using rigorous coupled wave analysis (RCWA).

45 35] Through the initial diffraction event, a set of possible light propagation angles $\theta_{S}(m)$ is defined for every wavelength $\lambda$. The above calculation is hence repeated for incidence angles $\theta_{S}(m)$ for both directions of incidence (top and bottom) and the results are stored in bidirectional scattering distribution functions $\operatorname{BSDF}(\lambda)$ with dimension equal to the number of propagating diffraction orders. Once the coherent optics of the solar cell stack and the nanostructure layer are calculated, they can be treated as interfaces [36] with angle dependent reflection, transmission or absorption coefficients. As described in [37, 38, the BSDF and the results from SETFOS are then used to calculate the optics of the incoherently coupled system, connected only through transparent thick layers (glass/polymer). From the resulting absorption in the active layer, the current 

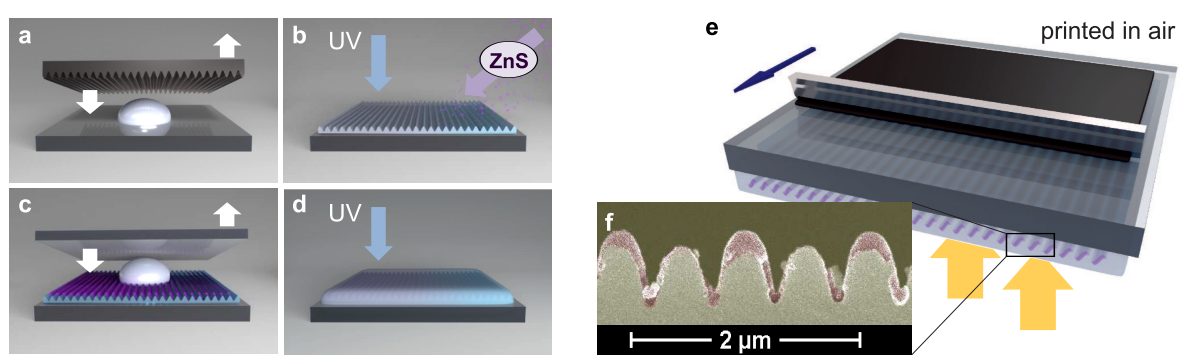

Figure 1: Fabrication of the light-management layer onto a solar cell substrate. (a) An UVcurable polymer is dispensed onto a large area and molded by a structured master. (b) After UV curing, a high-index zinc sulfide ( $\mathrm{ZnS}$ ) layer is obliquely evaporated onto the hardened structure. Through self-shadowing of the grating pillars an asymmetric layer is formed. (c)(d) A second layer of the polymer is then applied and cured to embed the $\mathrm{ZnS}$ nanostructure.

(e) The resulting diffractive film is attached to the substrate for printing of the photovoltaic layers. (f) SEM picture taken of the cross section of the high-index nanostructure layer.

density can be evaluated for various incident angles.

\section{Experimental}

\subsection{Device Fabrication}

In order to be compatible with large-area production, interference lithography [39] is used to create the designed nanostructure with period $\Lambda$ from which a nickel master is created. This template further enables cost-effective and large-ares continuous nanoimprint lithography [40, 41] through either hot embossing into flexible substrates or UV-lithography of a sol-gel [42, 14]. Fig. 1(a)-(d) show how the latter is used here to imprint an UV-curable polymer

(micro resist technology, OrmoStamp), which is dispensed over the full light incident side of the solar cell substrate. Once it is hardened on the area of 25 $\mathrm{cm}^{2}$ by UV light and successively baked it exhibits a high mechanical (hardness of $36 \mathrm{MPa}$, Young's modulus of $0.65 \mathrm{GPa}$ ) and thermal (up to $270^{\circ} \mathrm{C}$ ) stability and is further highly transparent for UV and visible light [43, 44. Tilted 70 evaporation $\left(45^{\circ}\right)$ of the transparent and high index-of-refraction material zinc sulfide $(\mathrm{ZnS})$ is used to obtain a periodically modulated asymmetric optical in- 
terface through self-shadowing of the previously molded pattern. [34] Once the structure is embedded with another layer of the UV-polymer it forms a selfcontained diffractive film, which is attached to the photovoltaic substrate. A SEM image of the final nanostructure is shown in Fig. 1(f) (Fig. S1) and reveals the $\mathrm{ZnS}$ coated side faces. Polymer solutions with standard architecture of ITO(150nm)/Clevios P-VP AI4083(30nm)/Merck Lisicon PV-D4610:PC ${ }_{60}$ BM $[1: 2](130 \mathrm{~nm}) / \mathrm{Ca}(30 \mathrm{~nm}) / \mathrm{Al}(100 \mathrm{~nm})$ were doctor-bladed in ambient atmosphere (Fig. 1) as described previously. 45] The standard device architecture and small device area is used to test the light management on an increased number of reference devices. Since the light management film is decoupled from the device and independent on its fabrication, no tests on durability or up-scaling of the organic solar cells are performed and can be found elsewhere. [46, 47, 48, 49]

\subsection{Sample characterization}

$\mathrm{J}-\mathrm{V}$ curves were recorded under illumination of 1 sun, provided by the xenon arc lamp of a solar simulator (sciencetech $\mathrm{SS} 2.5 \mathrm{~kW}$ ) equipped with an AM1.5 filter and a collimation of \pm 3 degrees. A power density of $100 \mathrm{~mW} \mathrm{~cm}^{-2}$ was ensured using a calibrated Si-photodiode (VLSI Standards). The samples were masked with an aperture of $A=0.04 \mathrm{~cm}^{2}$, mounted in a $\mathrm{N}_{2}$-filled housing and illuminated through a quartz window. A Keithley 2400 source meter was used to ramp the voltage from $-1.3 \mathrm{~V}$ to $1.3 \mathrm{~V}$ in steps of $0.01 \mathrm{~V}$ with a dwell time of 60 seconds to avoid heating of the device. The obtained current densities were multiplied with a correction factor accounting for the spectral mismatch and the Fresnel reflection at the quartz window $(n \approx 1.5)$. Additional data on statistical variations and error analysis can be found in Fig. S2. For angle dependent measurements a constant distance to the light source was ensured for all angles of incidence. External quantum efficiency (EQE) was measured in a $\mathrm{N}_{2}$-filled glovebox using the light of a xenon lamp passing through a monochromator and guided to the masked $\left(A=0.04 \mathrm{~cm}^{2}\right)$ sample through an optical fiber. Currents obtained from integration of the EQE-curves were compared to the values obtained from J-V measurements (see Fig. S3) yielding deviations 
below $6 \%$.

The diffraction efficiency of the nanostructure was measured with a semicylindrical glass lens attached on the backside of the sample to preserve the diffraction angle. Collimated white light was incident on the structure and intensity spectra were recorded behind the sample in steps of 2 degrees.

\section{Results and discussion}

110 (TIR) at the polymer-air interface $\theta_{T I R}$ and hence the light is largely hindered from escaping the device. Instead it is redirected back onto the diffractive layer and the PV stack as long as it leaves the device through a successive diffraction 
event ([A] or $[\mathrm{B}]$ in Fig. $2 \mathrm{a})$.

Fig. $2 \mathrm{p}$ shows the summed transmission efficiency $\eta_{ \pm 1}^{T}$ of the positive and negative first diffraction order for three nanostructure geometries. Starting with an $\mathrm{ZnS}$ coating that symmetrically follows a sines profile, we obtain a total efficiency of up to $70 \%$ equally split into both orders. In this case, however, due to reciprocity the light will escape the device upon incidence on the grating from below $([\mathrm{A}])$ as efficient as it is couples to the initial diffraction order (blue curve in Fig. 2.). Introducing an asymmetry into the coating gives rise to two effects: on the one hand the light is diffracted more efficient into the $T_{+1}$ order than into $T_{-1}$ and on the other hand the loss of this light is suppressed at the second diffraction event. The efficiency of this loss is indicated by the red line in Fig. 2(c) and corresponds to the light that after diffraction into $T_{+1}$ is reflected from the solar cell and escapes via diffraction at the nanostructure from below ([A] in Fig. 2a). It gets apparent, that for straight incidence this equals the inverse process for initial light, which is coupled into the weak $T_{-1}$ order (Fig. $2 \mathrm{~b}$, middle).

This asymmetry of $\eta_{+1}^{T}$ and $\eta_{-1}^{T}$ can be further enhanced by optimizing the shape of the nanostructure. This is achieved by changing the underlying periodic structure, indicated in Fig. $2 \mathrm{~b}$ (bottom) or the $\mathrm{ZnS}$ coating parameters (see Fig. S1). Through additional variation of period and depth, the nanostructure is optimized to yield the highest current density in the present solar cell. The fabricated structure slightly deviates from the theoretical maximum and is indicated by the blue cross in Fig. $2 \mathrm{~d}$ (see also Table S1). Fig. $2 \mathrm{~b}$ shows the measured $T_{+1}$ diffraction efficiency, which reveals a maximum of $\eta_{+1}^{T}=75 \%$ and an average of $\eta_{+1}^{T} \approx 60 \%$ between $450 \mathrm{~nm}<\lambda<750 \mathrm{~nm}$ in good agreement with the simulation. Despite the total amount of light in $T_{ \pm 1}$ is increased with respect to both sines shapes, at the same time the efficiency $\eta_{-1}^{T}$ is further reduced, which also reduces the loss through escape path $[\mathrm{A}]$ below $5 \%$. For a third diffraction event the portion of the light diffracted towards the surface ([B] in Fig. 2a and 2, remains below 3\% for $450 \mathrm{~nm}<\lambda<800 \mathrm{~nm}$ for all three 

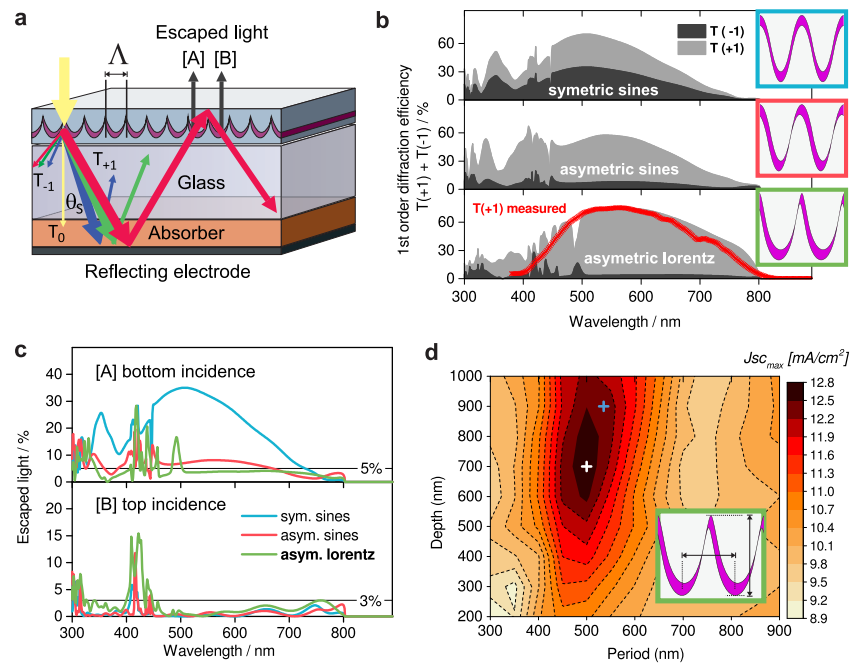

Figure 2: Design of the photonic nanostructure. (a) Sketch of the light path in the device with an embedded diffractive film. For $\Lambda \leq \lambda<n \Lambda$ the transmitted light of the first diffraction order $T_{+1}$ propagates with angle $\theta_{S}(\lambda)>\theta_{T I R}$ in the substrate and undergoes total internal reflection at the polymer-air interface (b) The sum of positive and negative first transmission orders and their ratio is strongly influenced by the shape of the nanostructure. (c) In contrast to symmetric shapes, the successive escape channels (A and B) can be suppressed with an asymmetric coating. (d) Dependent on period and depth of the nanostructure the structure can be optimized for highest current generation in the solar cell. The white cross marks the maximum, while the light blue cross indicates the structure fabricated in this work.

geometries.

\subsection{Absorption enhancement}

Fig. 3 a shows the electronic characterization of the fabricated devices with and without the light management. An average $10 \%$ increase in the short circuit current density $J_{S C}$ of devices with the light management film is obtained with respect to the reference devices. Since the structure does not interfere with the photoactive layer formation, we note that other electrical properties of the device remain unchanged (see Table 1). This leads to a direct translation of the enhancement onto the PCE of the device. The J-V curves of the best solar cells of each set are shown in Fig. 3b, which yield a representative 10.7\% increase in PCE, close to the average efficiency enhancement of $10.5 \%$. It has 

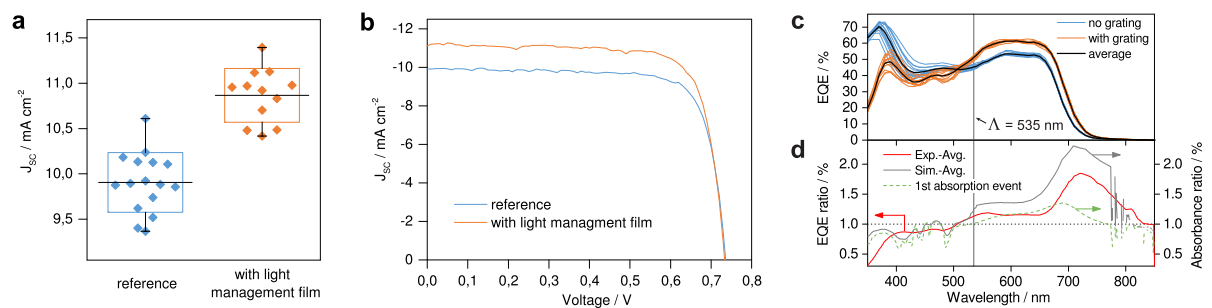

Figure 3: Photovoltaic device characterization. (a) Enhanced absorption through the light management film yields an increased short circuit current density $J_{S C}$ compared to the same device on an untreated substrate. (b) The JV-characteristics of the best device of each set reveal that the improvement in the current is directly converted into an enhanced overall output power of the device. (c) External quantum efficiency (EQE) of the solar cells with and without the attached light management layer. The vertical line indicates the nanostructure period $\Lambda=535 \mathrm{~nm}$. (d) Resulting averaged EQE enhancement ratio is in good agreement with the simulated absorption enhancement in the active layer.

to be emphasized that since our embedded light management film exhibits a unstructured sunward surface for functional reasons, no anti-reflection effect is provided by the embedded nanostructure. Simulations of the same material composition without patterning revealed an even higher reflectance compared to bare glass, which rules out the influence of reduced specular reflections due to additionally introduced surface layers (see Fig. S4), but emphasized the importance of the nanostructure design. However, as for any other flat (glass) surface, anti-reflection structures can be applied additionally or even imprinted in the outer cladding of the light management film (Fig. 1p-1d), which can give rise to an absorption increase of around $4 \%$ [24].

Fig. 35 shows the EQE for all devices with (orange) and without (blue) the light management layer. The average of the two sets is displayed as black line on top of the curves. A distinct enhancement in EQE is observed for $\lambda \geq \Lambda$, where the diffraction efficiency reaches a maximum and the diffraction angles exceed $\theta_{T I R}$ at the surface, which both leads to a more efficient light absorption. The ratio of the two black curves is shown as red line in Fig. 3 $\mathrm{d}$. It reveals a broadband enhancement starting at around $500 \mathrm{~nm}$ and exhibiting a maximum $(+85 \%)$ close to the band-edge of the photoactive layer at $720 \mathrm{~nm}$, which is 
Table 1: Photovoltaic parameters under AM1.5G illumination $\left(100 \mathrm{~mW} \mathrm{~cm}^{-2}\right)$.

\begin{tabular}{lllll} 
Substrate & $\begin{array}{l}V_{O C} \\
{[\mathbf{m V}]}\end{array}$ & $\begin{array}{l}\text { FF } \\
{[\%]}\end{array}$ & $\begin{array}{l}J_{S C}(\mathbf{m a x}) \\
{\left[\mathbf{m A ~} \mathbf{~ c m}^{-2}\right]}\end{array}$ & $\begin{array}{c}\text { PCE }(\mathbf{m a x}) \\
{[\%]}\end{array}$ \\
\hline & & & & \\
Reference & $720 \pm 10^{a)}$ & $76.4 \pm 1.7$ & $9.9 \pm 0.5(10.57)$ & $5.46 \pm 0.25(5.70)^{b)}$ \\
with optical film & $730 \pm 10$ & $75.8 \pm 2.3$ & $10.8 \pm 0.46(11.37)$ & $6.03 \pm 0.43(6.31)^{b)}$ \\
Enhancement & & & $\uparrow 9.8 \%(\uparrow 7.5 \%)$ & $\uparrow 10.5 \%(\uparrow 10.7 \%)$ \\
\hline
\end{tabular}

a) The stated error is the sum of the standard deviation $\sigma$ of the sets of 19 and 16 samples for reference and nanostructured substrate, respectively and the systematic error, which is estimated as $\sigma$ of multiple measurements of the same cell; ${ }^{b)}$ Shown in Fig. 1 , though the measured enhancement is a little lower for $\lambda>\Lambda$.

Using the optical model, it is possible to reveal the two enhancement mechanisms of the embedded nanostructure. If only the first diffraction and absorption event is taken into account and all reflected light is neglected, the dotted green curve in Fig. $3 \mathrm{~d}$ is obtained. This situation is comparable to symmetric airfaced nanostructures. It matches the experimental data well in regions where the materials absorption is strong $(580<\lambda<680 \mathrm{~nm})$, but it is not sufficient to reproduce the enhancement for larger wavelengths. If the successive diffraction events, however, are taken into account, the predicted enhancement increases and shifts towards the band-edge of the absorber $(+130 \%$ at $710 \mathrm{~nm})$, representing the light trapped in the device. It thereby contributes to the absorption as long as it travels within the geometric extend of the charge collecting electrode area. The shape of the electrode was not considered in our model and may be 


\section{Performance during a solar year}

\subsection{Simulations}

With the parameters of the fabricated nanostructure (Table S1) the absorption in the active layer $\operatorname{Abs}(\lambda, \theta)$ is simulated for two planes of incidence, which are spanned by the wavevector of the incident light and the surface normal and which can be either parallel (azimuthal angle $\phi=0^{\circ}$ ) or perpendicular $\left(\phi=90^{\circ}\right)$ to the grating vector $G$ (see Fig. 4). Additionally, for the asymmetric direction positive and negative angles have to be distinguished. For a given location (Latitude 47.565436, Longitude 7.602925) the Bird Simple Spectral Model (SPCTRAL2.xls), provided online by the U.S. Department of Energy (DOE)/NREL/ALLIANCE, was used to access the zenith angle, azimuth angle, spectrum and power density for every hour of the year. Since simulations were only done for $\phi=0^{\circ}, 90^{\circ}$, absorption of intermediate azimuthal angles $0^{\circ}<\phi<90^{\circ}$ was approximated to be linearly related to the extreme values and the current density is calculated by

$$
\begin{gathered}
J_{s c}=\frac{e}{h c} \int_{\lambda} \eta_{I Q E} \cdot\left[k(\phi) \cdot A b s_{\phi=90^{\circ}}(\lambda, \theta)\right. \\
\left.+(1-k(\phi)) \cdot A b s_{\phi=0^{\circ}}(\lambda, \theta)\right] \cdot S_{\phi, \theta}(\lambda) \lambda d \lambda,
\end{gathered}
$$

with $k(\phi)=\left|\phi / 90^{\circ}\right|$ for $\phi \leq 90^{\circ} ; k(\phi)=\left|\left(\phi-180^{\circ}\right) / 90^{\circ}\right|$ for $\phi>90^{\circ}$ and $\eta_{I Q E}$ set to 0.9 . Here, $e$ is the elementary charge, $h$ is Plank's constant and $c$ is the vacuum speed of light.

\subsection{Angle dependent measurements}

In order to access the impact of the light management for realistic operation conditions, angle dependent $\mathrm{J}-\mathrm{V}$ measurements were performed in steps of 5 degrees. Fig. 4 (a) shows the measured $J_{S C}$ for incident angles in the parallel case and in the perpendicular direction and the PCE at various angles of incidence is shown in Fig. 4(b). Along both directions the PCE enhancement through the light management can be kept over $\Delta \theta_{\phi=90^{\circ}}= \pm 40^{\circ}$ and $\Delta \theta_{\phi=0^{\circ}}= \pm 30^{\circ}$, respectively. Since independent on the location the angular span between summer 

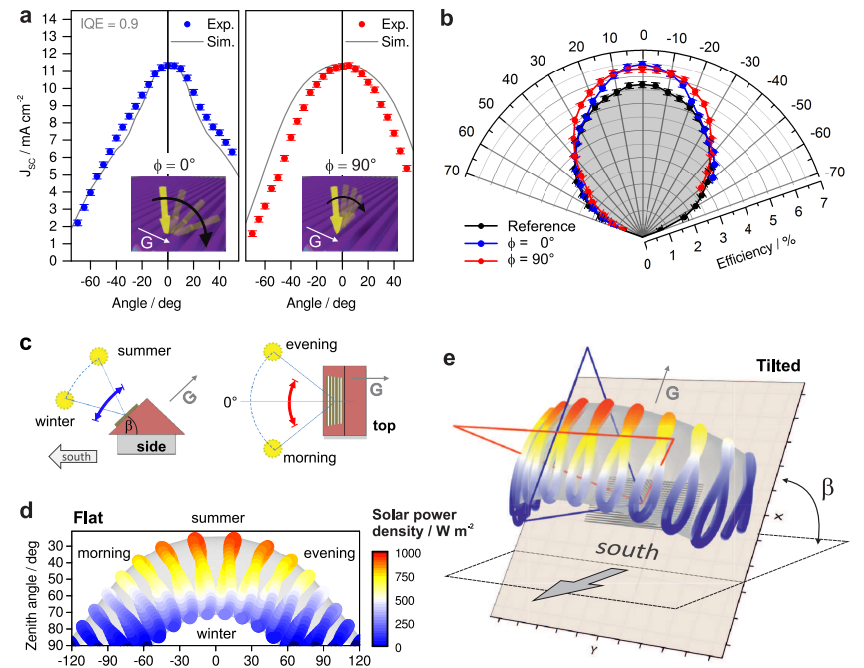

Figure 4: Yearly light harvesting with the light-managment. (a) Angle dependent short circuit current $J_{S C}$ of the device with the light management film, measured for two azimuth angles $\phi$ with respect to the grating vector $G$ and compared with the respective simulations. (b) Angle dependent efficiency for the two directions under simulated 1 sun illumination, compared to the reference device (shaded). (c) Sketch of the seasonal and daylight angles of incidence of the sun and (d) the corresponding solar power density of the respective position of the sun throughout the year calculated for Basel, Switzerland. (e) If the device with the light management is tilted by the latitude angle $\beta$, the angular span (red/blue cross) in which the conversion efficiency with the light management is superior to the reference covers the times of most powerful solar radiation.

and winter equals twice the equator's tilt with respect to the ecliptic $\left( \pm 23.4^{\circ}\right)$, this enhancement is already sufficient to improve the performance for all seasons if oriented properly (see Fig. 44) but a little to small for covering the whole daylight movement $\left( \pm 90^{\circ}\right)$.

\subsection{Yearly harvesting}

However, in terms of delivered power the sun's seasonal movement apparently exhibits a certain asymmetry. For locations outside the tropical zone, the proximity of the sun and hence the delivered power has its maximum in summer and decreases steadily towards winter as shown in Fig. 4d. In contrast, the 
daylight movement has its power maximum around noon and is symmetric with respect to morning or evening. Hence, a light management structure which exhibits an enhancement for a small range of angles $\theta_{\phi=0^{\circ}} \leq 25^{\circ}$ with high asymmetry but an enhancement for a preferably wide range of angles $\theta_{\phi=90^{\circ}}$ in the perpendicular direction with symmetric behavior is perfectly suited to maximize the energy harvested during a solar year. If we position our device facing south with a tilt equal to the local latitude $\beta$ as shown in Fig. 4e, we can cover the whole zenith angle distribution with our enhancement range $\left(\phi=0^{\circ}\right.$, blue bar) and most of the azimuthal distribution range $\left(\phi=90^{\circ}\right.$, red bar). Assuming clear sky conditions, an average fill factor of $70 \%$ and a constant $V_{O C}$ of 700 $\mathrm{mV}$, the energy harvested by the photovoltaic device without light management in this conditions can be approximated to be $77.0 \mathrm{kWh} \mathrm{m}^{-2}$ year ${ }^{-1}$. With the attached light management film, however, a generated energy of $87.4 \mathrm{kWh} \mathrm{m}^{-2}$ year $^{-1}(+13.4 \%)$ is obtained, increasing the yearly power conversion efficiency of the device in this configuration from $6.6 \%$ to $7.5 \%$.

\section{Conclusion}

In summary we presented an embedded light management film with an unstructured surface, which makes it durable and resistant to environmental and mechanical influences during photovoltaic operation. The self-contained film can be fabricated independent of the device by a mass-production compatible method and provides a perfect platform for future wavelength dependent optical engineering of preferable interference conditions in various thin film photovoltaic systems. In contrast to air-faced structures additionally light trapping yields up to $85 \%$ EQE increase near the band edge of the photoactive layer. The asymmetric structure leads to a highly efficient diffraction and secondly exhibits an angular performance dependence, which matches the distribution of incident solar power through the year. An overall enhancement at simulated standard test conditions of $11 \%$ is obtained and the yearly harvested energy was predicted to be increased by more than $13 \%$. Although the presented structure was op- 

is accessible through variations of the shape and structural parameters of the high-index nanostructure.

\section{Acknowledgements}

Funding: This work was performed in the framework of the EU project

\section{Appendix A. Supplementary Material}

Supplementary data associated with this article can be found online.

\section{References}

미 P. Jackson, R. Wuerz, D. Hariskos, E. Lotter, W. Witte, M. Powalla, Effects 285 of heavy alkali elements in cu(in, ga)se2solar cells with efficiencies up to

22.6\%, Phys. Status Solidi RRL 10 (8) (2016) 583-586. doi:10.1002/ pssr.201600199.

URL http://dx.doi.org/10.1002/pssr.201600199

¿ [2] M. A. Green, K. Emery, Y. Hishikawa, W. Warta, E. D. Dunlop, Solar 290 cell efficiency tables (version 48), Progress in Photovoltaics: Research and Applications 24 (7) (2016) 905-913. doi:10.1002/pip.2788

URL http://dx.doi.org/10.1002/pip.2788

[3] M. Saliba, T. Matsui, K. Domanski, J.-Y. Seo, A. Ummadisingu, S. M. Zakeeruddin, J.-P. Correa-Baena, W. R. Tress, A. Abate, A. Hagfeldt, 
M. Grätzel, Incorporation of rubidium cations into perovskite solar cells improves photovoltaic performance, Science 354 (6309) (2016) 206209. arXiv:http://science.sciencemag.org/content/354/6309/206. full.pdf doi:10.1126/science.aah5557.

URL http://science.sciencemag.org/content/354/6309/206

[4] W. Wang, M. T. Winkler, O. Gunawan, T. Gokmen, T. K. Todorov, Y. Zhu, D. B. Mitzi, Device characteristics of cztsse thin-film solar cells with $12.6 \%$ efficiency, Advanced Energy Materials 4 (7) (2014) 1301465-n/a, 1301465. doi:10.1002/aenm.201301465.

URL http://dx.doi.org/10.1002/aenm.201301465

[5] G. Larramona, S. Levcenko, S. Bourdais, A. Jacob, C. Chon, B. Delatouche,

a C. Moisan, J. Just, T. Unold, G. Dennler, Fine-tuning the sn content in a cztsse thin films to achieve $10.8 \%$ solar cell efficiency from spray-deposited waterethanol-based colloidal inks, Advanced Energy Materials 5 (24) (2015) 1501404-n/a, 1501404. doi:10.1002/aenm. 201501404.

URL http://dx.doi.org/10.1002/aenm.201501404

[ [6] J. Zhao, Y. Li, G. Yang, K. Jiang, H. Lin, H. Ade, W. Ma, H. Yan, Efficient organic solar cells processed from hydrocarbon solvents, Nature Energy 1 (2) (2016) 15027. doi:10.1038/nenergy.2015.27.

URL http://dx.doi.org/10.1038/NENERGY.2015.27

${ }_{315}^{\text {口[ }}$ [7] W. Zhao, D. Qian, S. Zhang, S. Li, O. Inganäs, F. Gao, J. Hou, Fullerene-

1. free polymer solar cells with over $11 \%$ efficiency and excellent thermal stability, Adv. Mater.doi:10.1002/adma.201600281.

URL http://dx.doi.org/10.1002/adma.201600281

q [8] M. Graetzel, R. A. J. Janssen, D. B. Mitzi, E. H. Sargent, Materials in320 terface engineering for solution-processed photovoltaics, Nature 488 (7411) (2012) 304-312. doi:10.1038/nature11476. URL http://dx.doi.org/10.1038/nature11476 
[9] J. R. Tumbleston, B. A. Collins, L. Yang, A. C. Stuart, E. Gann, W. Ma,

W. You, H. Ade, The influence of molecular orientation on organic bulk heterojunction solar cells, Nature Photonics 8 (5) (2014) 385-391. doi: 10.1038/nphoton. 2014.55.

URL http://dx.doi.org/10.1038/Nphoton.2014.55

[10] S.-H. Bae, H. Zhao, Y.-T. Hsieh, L. Zuo, N. D. Marco, Y. S. Rim, G. Li, Y. Yang, Printable solar cells from advanced solution-processible materials, Chem 1 (2) (2016) 197-219. doi:10.1016/j.chempr.2016.07.010.

URL http://dx.doi.org/10.1016/j.chempr .2016.07.010

[11] Z. Tang, W. Tress, O. Inganäs, Light trapping in thin film organic solar

口. cells, Materials Today 17 (8) (2014) 389-396. doi:10.1016/j.mattod. 2014.05 .008 URL http://dx.doi.org/10.1016/j.mattod.2014.05.008

[12] M. Burresi, F. Pratesi, F. Riboli, D. S. Wiersma, Complex photonic structures for light harvesting, Advanced Optical Materials 3 (6) (2015) 722-743. doi:10.1002/adom.201400514.

URL http://dx.doi.org/10.1002/adom.201400514

[13] Q.-D. Ou, Y.-Q. Li, J.-X. Tang, Light manipulation in organic photo1. voltaics, Advanced Science 3 (7) (2016) 1600123-n/a, 1600123. doi: 10.1002/advs.201600123.

URL http://dx.doi.org/10.1002/advs. 201600123

[14] M. L. Brongersma, Y. Cui, S. Fan, Light management for photovoltaics using high-index nanostructures, Nature Materials 13 (5) (2014) 451-460. doi:10.1038/nmat3921.

URL http://dx.doi.org/10.1038/nmat3921

[15] S. Mokkapati, K. R. Catchpole, Nanophotonic light trapping in solar cells, J. Appl. Phys. 112 (10) (2012) 101101. doi:10.1063/1.4747795 
[16] C. Battaglia, J. Escarré, K. Söderström, M. Charrière, M. Despeisse, F.-

J. Haug, C. Ballif, Nanomoulding of transparent zinc oxide electrodes for efficient light trapping in solar cells, Nature Photonics 5 (9) (2011) 535-

538. doi:10.1038/nphoton.2011.198

URL http://dx.doi.org/10.1038/nphoton.2011.198

[17] C.-C. Chueh, M. Crump, A. K.-Y. Jen, Optical enhancement via electrode designs for high-performance polymer solar cells, Adv. Funct. Mater. 26 (3) (2015) 321-340. doi:10.1002/adfm. 201503489.

URL http://dx.doi.org/10.1002/adfm.201503489

[18] H. A. Atwater, A. Polman, Plasmonics for improved photovoltaic devices Nature Materials 9 (3) (2010) 205-213. doi:10.1038/nmat2629.

URL http://dx.doi .org/10.1038/nmat2629

[19] Q. Gan, F. J. Bartoli, Z. H. Kafafi, Plasmonic-enhanced organic photovoltaics: Breaking the 10\% efficiency barrier, Adv. Mater. 25 (17) (2013) 2385-2396. doi:10.1002/adma.201203323

URL http://dx.doi.org/10.1002/adma. 201203323

[20] V. K. Narasimhan, Y. Cui, Nanostructures for photon management

1. in solar cells, Nanophotonics 2 (3) (2013) 187-210. doi:10.1515/ nanoph-2013-0001.

URL http://dx.doi .org/10.1515/nanoph-2013-0001

[21] F. Priolo, T. Gregorkiewicz, M. Galli, T. F. Krauss, Silicon nanostructures

1. for photonics and photovoltaics, Nature Nanotech 9 (1) (2014) 19-32. doi: 10.1038/nnano.2013.271.

URL http://dx.doi .org/10.1038/nnano.2013.271

375 [22] W. Cao, J. Xue, Recent progress in organic photovoltaics: device architecture and optical design, Energy \& Environmental Science 7 (7) (2014) 2123. doi:10.1039/c4ee00260a.

URL http://dx.doi.org/10.1039/c4ee00260a 
[23] C. Cho, H. Kim, S. Jeong, S.-W. Baek, J.-W. Seo, D. Han, K. Kim, Y. Park, ping in organic photovoltaic cells, Solar Energy Materials and Solar Cells 115 (2013) 36-41. doi:10.1016/j.solmat.2013.03.014.

URL http://dx.doi.org/10.1016/j.solmat.2013.03.014

[24] K. Forberich, G. Dennler, M. C. Scharber, K. Hingerl, T. Fromherz, C. J. Brabec, Performance improvement of organic solar cells with moth eye

1. anti-reflection coating, Thin Solid Films 516 (20) (2008) 7167-7170. doi: $10.1016 / j . t s f .2007 .12 .088$

URL http://dx.doi.org/10.1016/j.tsf .2007.12.088

[25] J. D. Myers, W. Cao, V. Cassidy, S.-H. Eom, R. Zhou, L. Yang, W. You, J. Xue, A universal optical approach to enhancing efficiency of organicbased photovoltaic devices, Energy \& Environmental Science 5 (5) (2012) 6900. doi:10.1039/c2ee21254d. URL http://dx.doi.org/10.1039/c2ee21254d

[26] S. Esiner, T. Bus, M. M. Wienk, K. Hermans, R. A. J. Janssen, Quantifi$395 \quad \square$ cation and validation of the efficiency enhancement reached by application of a retroreflective light trapping texture on a polymer solar cell, Advanced Energy Materials 3 (8) (2013) 1013-1017. doi:10.1002/aenm.201300227 URL http://dx.doi.org/10.1002/aenm.201300227

[27] J. Yun, W. Wang, S. M. Kim, T.-S. Bae, S. Lee, D. Kim, G.-H. Lee, 400 ․ H.-S. Lee, M. Song, Light trapping in bendable organic solar cells using 1. Silica nanoparticle arrays, Energy Environ. Sci. 8 (3) (2015) 932-940. doi: $10.1039 / \mathrm{c} 4 \mathrm{ee} 01100 \mathrm{~g}$ URL http://dx.doi.org/10.1039/c4ee01100g

[28] G. Kang, K. Bae, M. Nam, D.-H. Ko, K. Kim, W. J. Padilla, Broadband $405 \quad$ and ultrahigh optical haze thin films with self-aggregated alumina nanowire bundles for photovoltaic applications, Energy Environ. Sci. 8 (9) (2015) 
2650-2656. doi:10.1039/c5ee01757b.

URL http://dx.doi .org/10.1039/c5ee01757b

[29] L. van Dijk, E. P. Marcus, A. J. Oostra, R. E. Schropp, M. D. Vece, 3d-printed concentrator arrays for external light trapping on thin film solar cells, Solar Energy Materials and Solar Cells 139 (2015) 19 - 26. doi:http://dx.doi.org/10.1016/j.solmat.2015.03.002. URL http://www.sciencedirect.com/science/article/pii/ S0927024815001075

${ }_{415}^{[}[30]$ R. Lampande, G. W. Kim, M. J. Park, B. Y. Kang, J. H. Kwon, Efघ ficient light harvesting in inverted polymer solar cells using polymeric 2d-microstructures, Solar Energy Materials and Solar Cells 151 (2016) 162 - 168. doi:http://dx.doi.org/10.1016/j.solmat.2016.03.005.

II URL http://www.sciencedirect.com/science/article/pii/ S092702481600101X

[31] Y. Park, J. Berger, Z. Tang, L. Mller-Meskamp, A. F. Lasagni, K. Vandewal, K. Leo, Flexible, light trapping substrates for or-

(1) ganic photovoltaics, Applied Physics Letters 109 (9). doi:http: //dx.doi.org/10.1063/1.4962206

URL http://scitation.aip.org/content/aip/journal/apl/109/9/ $10.1063 / 1.4962206$

[32] J. Ham, W. J. Dong, G. H. Jung, J.-L. Lee, Wavelength-scale structures as extremely high haze films for efficient polymer solar cells, ACS Appl. Mater. Interfaces 8 (9) (2016) 5990-5997. doi:10.1021/acsami.5b11061 URL http://dx.doi.org/10.1021/acsami.5b11061

[33] C. Cho, S. Jeong, H.-J. Choi, N. Shin, B. Kim, E.-c. Jeon, J.-Y. Lee, Toward a perfect light trapping in thin-film photovoltaic cells: Full utilization of the dual characteristics of light, Advanced Optical Materials 3 (12) (2015) 1697-1702. doi:10.1002/adom.201500471. URL http://dx.doi.org/10.1002/adom.201500471 
[34] F. Lütolf, M. Stalder, O. J. F. Martin, Up-scalable method to amplify the diffraction efficiency of simple gratings, Optics Letters 39 (23) (2014) 6557. doi:10.1364/ol.39.006557.

URL http://dx.doi.org/10.1364/OL.39.006557

[35] M. G. Moharam, T. K. Gaylord, Rigorous coupled-wave analysis of planar-grating diffraction, J. Opt. Soc. Am. 71 (7) (1981) 811-818. doi:10.1364/JOSA.71.000811. URL http://www.osapublishing.org/abstract.cfm?URI= josa $-71-7-811$

${ }_{445}^{4}[36]$ T. Lanz, B. Ruhstaller, C. Battaglia, C. Ballif, Extended light scattering model incorporating coherence for thin-film silicon solar cells, J. Appl. Phys. 110 (3) (2011) 033111. doi:10.1063/1.3622328.

URL http://dx.doi.org/10.1063/1.3622328

[37] J. Eisenlohr, N. Tucher, O. Höhn, H. Hauser, M. Peters, P. Kiefel, J. C. Goldschmidt, B. Bläsi, Matrix formalism for light propagation and absorption in thick textured optical sheets, Opt. Express 23 (11) (2015) A502. doi:10.1364/oe.23.00a502

URL http://dx.doi.org/10.1364/0E.23.00A502

[38] N. Tucher, J. Eisenlohr, H. Gebrewold, P. Kiefel, O. Höhn, H. Hauser, J. C. Goldschmidt, B. Bläsi, Optical simulation of photovoltaic modules ם with multiple textured interfaces using the matrix-based formalism OPTOS, Opt. Express 24 (14) (2016) A1083. doi:10.1364/oe.24.0a1083. URL http://dx.doi.org/10.1364/OE.24.0A1083

[39] temicon GmbH, UV-Lithography, online, accessed on Dec 22th, 2016: http://www.temicon.com/en/technologien/photolithographie/ (December 2016).

URL http://www.temicon.com/en/technologien/photolithographie/

[40] J. A. Liddle, G. M. Gallatin, Nanomanufacturing: A perspective, ACS 
Nano 10 (3) (2016) 2995-3014. doi:10.1021/acsnano.5b03299.

[41] W. Qiao, W. Huang, Y. Liu, X. Li, L.-S. Chen, J.-X. Tang, Toward scalable flexible nanomanufacturing for photonic structures and devices, Advanced Materialsdoi:10.1002/adma.201601801.

URL http://dx.doi .org/10.1002/adma.201601801

[42] H.-J. Kim, M. Almanza-Workman, B. Garcia, O. Kwon, F. Jeffrey, S. Braymen, J. Hauschildt, K. Junge, D. Larson, D. Stieler, A. Chaiken, B. Cobene, R. Elder, W. Jackson, M. Jam, A. Jeans, H. Luo, P. Mei, C. Perlov, C. Taussig, Roll-to-roll manufacturing of electronics on flexible substrates using self-aligned imprint lithography (SAIL), Journal of the Society for Information Display 17 (11) (2009) 963. doi:10.1889/jsid17.11.963.

URL http://dx.doi.org/10.1889/JSID17.11.963

[43] micro resist technology GmbH, OrmoStamp datasheet, online, accessed on Dec 15th, 2016: http://microresist.de/sites/default/files/ download/PI_OrmoStamp_2015.pdf (December 2016).

URL http://microresist.de/sites/default/files/download/PI_ OrmoStamp_2015.pdf

[44] G. Gruetzner, J. Klein, M. Vogler, A. Schleunitz, UV-curable hybrid 口 polymers for optical applications: technical challenges, industrial solutions, and future developments, in: G. von Freymann, W. V. Schoenfeld, R. C. Rumpf (Eds.), Advanced Fabrication Technologies for Micro/Nano Optics and Photonics VII, SPIE-Intl Soc Optical Eng, 2014. doi:10.1117/12.2043038,

URL http://dx.doi.org/10.1117/12.2043038

[45] J. Mayer, B. Gallinet, T. Offermans, R. Ferrini, Diffractive nanostructures for enhanced light-harvesting in organic photovoltaic devices, Opt. Express 24 (2) (2015) A358. doi:10.1364/oe.24.00a358.

URL http://dx.doi.org/10.1364/OE.24.00A358 
[46] F. C. Krebs, Fabrication and processing of polymer solar cells: A review of printing and coating techniques, Solar Energy Materials and Solar Cells 93 (4) (2009) 394-412. doi:10.1016/j.solmat.2008.10.004

URL http://dx.doi.org/10.1016/j.solmat.2008.10.004

[47] R. Søndergaard, M. Hösel, D. Angmo, T. T. Larsen-Olsen, F. C. Krebs, Roll-to-roll fabrication of polymer solar cells, Materials Today 15 (1-2) (2012) 36-49. doi:10.1016/s1369-7021(12)70019-6 URL http://dx.doi.org/10.1016/S1369-7021(12)70019-6

[48] Q. Bao, X. Liu, S. Braun, M. Fahlman, Oxygen- and water-based degradation in [6, 6]-phenyl-c 61 -butyric acid methyl ester (PCBM) films, Advanced Energy Materials 4 (6) (2013) 1301272. doi:10.1002/aenm. 201301272 . URL http: //dx.doi.org/10.1002/aenm. 201301272

[49] A. Guerrero, H. Heidari, T. S. Ripolles, A. Kovalenko, M. Pfannmöller, S. Bals, L.-D. Kauffmann, J. Bisquert, G. Garcia-Belmonte, Shelf life n degradation of bulk heterojunction solar cells: Intrinsic evolution of charge

【 transfer complex, Advanced Energy Materials 5 (7) (2014) 1401997. doi: 10.1002/aenm. 201401997 .

URL http://dx.doi.org/10.1002/aenm. 201401997

[50] L. A. A. Pettersson, L. S. Roman, O. Inganas, Modeling photocurrent action spectra of photovoltaic devices based on organic thin films, J. Appl. Phys. 86 (1) (1999) 487. doi:10.1063/1.370757. URL http://dx.doi.org/10.1063/1.370757

[51] G. Dennler, K. Forberich, M. C. Scharber, C. J. Brabec, I. Tomis, K. Hingerl, T. Fromherz, Angle dependence of external and internal quantum efficiencies in bulk-heterojunction organic solar cells, J. Appl. Phys. 102 (5) (2007) 054516. doi:10.1063/1.2777724

URL http://dx.doi.org/10.1063/1.2777724 
[52] J. Mescher, A. Mertens, A. Egel, S. W. Kettlitz, U. Lemmer, A. Colsmann,

I. Illumination angle and layer thickness influence on the photo current generation in organic solar cells: A combined simulative and experimental study, AIP Advances 5 (7) (2015) 077188. doi:10.1063/1.4928074. 